\title{
Effect of Short-Term Practice of Bhramari Pranayama on Sleep Quality and Perceived Stress in School Students
}

\author{
Abhishek Kumar' ${ }^{1}$, Venkatesh $\mathbf{S}^{2}$

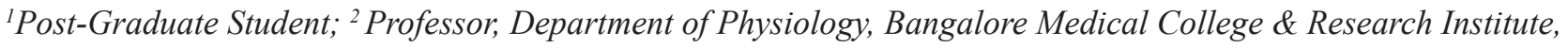 \\ Fort, K. R. Road, Bengaluru, India
}

\begin{abstract}
Background: In today's highly-competitive era of modern education, students are constantly exposed to 'high' academic stress. Stress, in turn, affects sleep quality. Deterioration in sleep quality adversely affects overall health. Yogic breathing exercise i.e., 'Pranayama' practice is an easy yet effective way to maintain sound physical and mental health. Traditional yogic literatures particularly recommend 'Bhramari' Pranayama (the 'Humming Bee' breath) for effectively reducing stress and improving quality of sleep. Due to lack of specific scientific evidence to support these benefits from Bhramari Pranayama, this study was undertaken to evaluate the effect of Bhramari Pranayama practice on sleep quality and perceived stress in school students.
\end{abstract}

Objectives: To evaluate the effect of short-term (6 weeks) practice of Bhramari Pranayama on Sleep Quality and Perceived Stress in school students.

Methodology: After obtaining Ethical clearance, 60 school students of class X were randomly selected for the study. Assent from participants and written informed consent from their parents were obtained. After history-taking and general physical examination, 'baseline' data including assessment of Sleep quality and Perceived stress were obtained using the PSQI (Pittsburgh Sleep Quality Index) and PSS (Perceived Stress Scale) questionnaires respectively. Thereafter, Bhramari Pranayama was practiced by the students for 6 weeks. Finally, at the end of 6 weeks sleep quality and perceived stress were re-assessed using the above questionnaires. Pre- and post- Bhramari pranayama data were compared and analysed using descriptive statistics and Student's t-test; $p$-value $<0.05$ was considered as statistically significant.

Results: Post Bhramari Pranayama practice, there was significant improvement in Sleep quality \& a significant reduction in Perceived stress ( $\mathrm{p}$-value $<0.05$ ).

Conclusion: Hence, just a few weeks practice of Bhramari Pranayama significantly improves sleep quality and reduces perceived stress.

Keywords: Academic stress, Bhramari Pranayama, Perceived Stress, Sleep Quality

\section{Introduction}

Today, while India gropes with the achievement of a target "Education for All", another set of problems

\footnotetext{
Corresponding author:

Dr. Venkatesh S.,

Professor, Department of Physiology,

Bangalore Medical College \& Research Institute, Fort,

K. R. Road, Bengaluru-560002, Karnataka, India.

Venkie1971@rediffmail.com
}

concerning the educationalists in the country today are issues related to the ever-increasing burden of high 'academic stress' and their adverse effects on students. ${ }^{1}$ Various studies carried out after the year 2000 revealed a significantly high prevalence of academic stress among Indian students. One of the studies by Deb et al. in the year 2015 revealed that nearly two-thirds $(63.5 \%)$ of the Indian students reported stress due to high academic pressure. $^{2}$ 
Chronic high-academic stress adversely affects student's learning process and overall health. ${ }^{3}$ Apart from having a plethora of ill-effects on almost all the major physiological systems of the body, prolonged stress also affects the quality of sleep adversely. Again, the deterioration in sleep quality, in turn affects the overall health. ${ }^{4}$

'Pranayama', a form of Yogic-breathing exercise, has proved to be an easy yet effective way to maintain a sound physical and mental health. ${ }^{5}$ The Sanskrit word 'Pranayama' has been derived from two root words namely- 'Prana' (meaning Vital force) \&, 'Yama' (meaning Regulation). Hence, 'Pranayama' literally means- a yogic act regulating flow of the vital energy that governs all the physiological processes in the body. ${ }^{6}$ While there are different forms of Pranayama, the 'Bhramari' Pranayama (also known as 'the HummingBee' breath) is well-known for its multiple healthbenefits. $^{7}$

Also, some of its special features which make this Pranayama notifiable are- its simplicity of slow breathing, complemented with the 'Humming' sound (to be produced during expiration) which makes it more interesting to perform, \& finally the fact that it can be easily practiced by everyone, irrespective of age \& gender. ${ }^{6}$ Along with its numerous other health benefits, Bhramari Pranayama is recommended by the traditional yogic-literatures particularly for: effectively reducing stress and improving the quality of sleep. ${ }^{8}$ However, there is no modern scientific evidence to support these specific benefits from Bhramari Pranayama.

Hence this study was undertaken, to evaluate the effect of Bhramari Pranayama practice on sleep quality and perceived stress in school students.

\section{Objectives:}

To evaluate the effect of short-term (6 weeks) practice of Bhramari Pranayama on Sleep Quality and Perceived Stress in school students.

\section{Methodology}

After obtaining ethical clearance from the Institutional Ethics Committee of BMC\&RI, Bengaluru, as well as obtaining a written permission from the head of the school, students were randomly selected from class X of a private school in South Bengaluru for this 'Experimental study' which was conducted during December 2019 to January 2020. Subjects were recruited based on the following Eligibility criteria:

\section{Inclusion criteria: -}

1. Age-group: 15-17 years.

2. Apparently healthy students.

3. Subjects who voluntarily gave an Assent to participate in the study and, who also provided a writteninformed consent from their parents.

Exclusion criteria: -

1. Subjects with sleep, anxiety/psychiatric disorders.

2. Subjects with ear, respiratory tract infections.

3. Recent history of surgery of ear/ vocal apparatus.

4. History of any other acute/chronic illness.

5. Subjects on regular medication, especially on CNS drugs.

6. Those practicing any form of Pranayama, Yoga, Meditation or other relaxation techniques for past one year.

After explaining about the study in detail and procuring a relevant history and General physical examination, finally 60 school students of class $\mathrm{X}$ of both genders were enrolled for the study. At first the 'baseline' data, including assessment of Sleep quality and Perceived Stress, were obtained using the PSQI (Pittsburgh Sleep Quality Index) and the PSS-10 (Perceived Stress Scale) questionnaires respectively, before the actual training and practice started.

\section{The Pittsburgh Sleep Quality Index (PSQI)}

The Pittsburgh Sleep Quality Index (PSQI) is a standardized, self-rated questionnaire which was designed to measure sleep quality and sleep disturbances in clinical population. The PSQI questionnaire asks subjects to rate their sleep quality and disturbances over the last month preceding test administration. This 19-item questionnaire generates seven component scores, with 
subscale scores 0 to 3, for the following 7 componentsSubjective sleep quality, sleep latency, sleep duration, habitual sleep efficiency, sleep disturbances, use of sleep medication, and Daytime dysfunction. Adding up of scores from these 7 components yields a 'Global PSQI score' of Sleep quality. The global score ranges from 0 to 21 ; a score measuring $<5$ indicates 'Good' sleep quality, whereas a score of $\geq 5$ is indicative of a 'Poor' sleep quality. The sensitivity of the tool is $89.6 \%$ and specificity is $86.5 \%$ in distinguishing good and poor sleepers. PSQI has good reliability with high internal consistency $(\alpha=0.83)$ and a good test-retest reliability $(\mathrm{r}=0.85){ }^{9}$

\section{Perceived Stress Scale (PSS-10)}

The Perceived Stress Scale is a classic stress assessment tool which remains the most widely used psychological instrument for measuring the 'perception of stress'. It is a measure of the degree to which situations in one's life are appraised as 'stressful'. The questions in this scale ask about the feelings and thoughts of the participants during the last month. The questions are of a general nature and hence are relatively free of content specific to any subpopulation group. The PSS10 questionnaire consists of 10 items, with each item rated on a 5-point Likert scale ranging from 'never' (0) to 'very often' (4). Positively worded items are 'reverse' scored, and then the ratings are summed across all 10 items, with 'higher' scores indicating 'more' perceived stress. Total score ranges from 0 to 40 . Score of $0-13$ is considered low stress, $14-26$ is moderate stress \& $27-40$ is severe stress. ${ }^{10}$

After obtaining 'baseline' data including assessment of Sleep quality and Perceived stress at the baseline, subjects were trained by a certified Yoga-instructor for 1 session to perform Bhramari pranayama as per the standard method, ${ }^{11}$ with following instructions: "sit in a comfortable posture with the eyes closed, close the ears with thumbs, place the index fingers on the forehead right above eyebrows $\&$ the other 3 fingers by the side of nose, slowly inhale through the nose, keeping the mouth closed, slowly \& deeply exhale by making a 'humming' sound (like a bumble-bee)". The rate at which the participants were asked to perform the Pranayama was: 3-4 Bhramari breaths/minute, for 5 minutes, followed by 2 minutes of rest. This was considered ' 1 cycle'. 5 cycles were performed in a 45 minutes session per day, for 6 days a week, for 6 continuous weeks.

At the end of 6 weeks, Sleep quality and Perceived stress were reassessed using the above questionnaires, and their scores of Pre- and Post- Bhramari Pranayama practice were compared and statistically analysed.

\section{Statistical Analysis}

Statistical analysis was performed using SPSS software (version 25.0, IBM). Data were presented as 'mean \pm standard deviation'. Student's t-test (two tailed) was used to compare the groups. p-value $<0.05$ was considered as statistically significant.

\section{Results}

A total of 60 subjects including 30 males and 30 females were included in the study. Mean age of the participants was $15.77 \pm 0.11$ yrs.

Table 1 shows 'Baseline-data' for the study participants.

Table 1: 'Baseline' Demographic, Sleep quality (PSQI score) \& Perceived stress (PSS score) Data-

\begin{tabular}{|l|l|l|l|l|}
\hline VARIABLES & MALE & FEMALE & TOTAL & p-value \\
\hline Number & 30 & 30 & 60 & - \\
\hline Age (years) & $15.82 \pm 0.13$ & $15.72 \pm 0.09$ & $15.77 \pm 0.11$ & 0.202 \\
\hline BMI (Kg/m2) & $20.33 \pm 0.76$ & $20.52 \pm 0.44$ & $20.43 \pm 0.6$ & 0.486 \\
\hline PSQI score & $5.29 \pm 0.51$ & $6.1 \pm 1.09$ & $5.7 \pm 0.57$ & 0.143 \\
\hline PSS score & $19.1 \pm 2.06$ & $20.2 \pm 1.87$ & $19.65 \pm 1.28$ & 0.385 \\
\hline
\end{tabular}


Table 2 shows the effect of short-term practice of Bhramari Pranayama on sleep quality and perceived stress in the study participants.

Table 2: Comparison of Sleep quality (PSQI score) \& Perceived stress (PSS score) before \& after 6 weeks practice of Bhramari pranayama-

\begin{tabular}{|l|l|l|l|}
\hline VARIABLES & Pre-Pranayama & Post-Pranayama & p-value \\
\hline PSQI score & $5.7 \pm 0.57$ & $3.82 \pm 0.33$ & $<\mathbf{0 . 0 0 0 1} *$ \\
\hline PSS score & $19.65 \pm 1.28$ & $12.2 \pm 0.86$ & $<\mathbf{0 . 0 0 0 1} *$ \\
\hline
\end{tabular}

$(*$ p-value $<0.05)$

\section{PSQI: Pittsburgh Sleep Quality Index}

PSS: Perceived Stress Scale

Bhramari Pranayama practice even for a relatively short duration of 6 weeks led to a significant $(\mathrm{p}<0.05)$ decrement in scores of both PSQI and PSS, indicative of a significant improvement in Sleep quality and significant reduction in Perceived stress.

\section{Discussion}

The present study revealed that practicing Bhramari pranayama even for a relatively short duration of six weeks significantly improves sleep quality and decreases perceived stress.

Pranayama practice is believed to have multiple health benefits and many studies have been conducted in the past experimenting these benefits, still there is very little documentation on benefits of 'specific' pranayama individually. The Bhramari pranayama is one such technique that has got numerous health benefits but, on the contrary, has very little scientific evidence showing its specific health effects. Most of the literatures available are the 'shared effects' of Bhramari pranayama practice along with other Pranayamas together, and very less effort has been put in the past to decipher the various health benefits of Bhramari pranayama individually ${ }^{6}$. As the per the knowledge of the authors, this study is the first scientific attempt to verify the claims made by traditional yogic-texts that Bhramari pranayama practice is one of the most effective ways to treat sleep related disorders by improving the overall quality of sleep, and to effectively reduce stress levels ${ }^{8}$. Following are the findings of some of the studies done previously to investigate the benefits from Bhramari pranayama practice.

In a study done in the year 2010 by Pramanik et al. to find the Immediate effect of Bhramari pranayama practice, they concluded that slow Bhramari breathing just for five minutes balances the autonomic nervous system through enhanced activation of the parasympathetic system and can be practiced for mental relaxation and reduction of stress in daily life ${ }^{6}$. In another study titled 'EEG paroxysmal gamma waves during Bhramari Pranayama: A yoga breathing technique' done by Vialatte et al. in 2008, they found that Bhramari pranayama practice has a significant influence on the brain activity and induces a feeling of "blissfulness" ${ }^{12}$. In their study titled 'Role of self-induced sound therapy: Bhramari Pranayama in Tinnitus', Pandey et al. concluded that Bhramari pranayama practice promotes parasympathetic predominance and it significantly reduces the irritability, depression and anxiety associated with tinnitus ${ }^{13}$.

Although none of the previous studies have clearly elucidated the 'exact' mechanisms behind how Bhramari Pranayama practice brings about the desired effects, here the improvement in sleep quality and reduction in stress could be due to the following reasonsBhramari pranayama practice ramps up the production of Nitric oxide (NO), which apart from having several other key health benefits, also improves the quality of sleep. It is estimated that 'humming' during the exhalation phase of Bhramari pranayama increases the endogenous generation of nitric oxide levels by 15 -fold as compared to quite exhalation. This in turn helps to dilate the arteries, improve blood circulation and the tissue oxygenation ${ }^{14}$. The 'Acoustic vibration' produced by the humming sound acts as a beneficial stimulus 
for the brain tissues, helps to soothe the brain and the nerves and thus has a significant impact in producing the desired effects ${ }^{8}$. Also, the 'self-induced humming sound' in this practice resembles mantra-meditation technique, and induces subjective feelings of mind refreshment and blissfulness ${ }^{6}$. All the previous studies directly or indirectly have found the effect of Bhramari Pranayama practice leading to 'Parasympathetic dominance', thus causing reduction in stress levels and a more calm state of mind, and hence an improved quality of sleep ${ }^{6}$. Further, the neural respiratory elements may be responsible for a mechanism that brings about the above effects as Bhramari Pranayama practice modifies the normal breathing rhythm, with prolonged exhalation $\&$ short inhalation, and thus produces significant impact in the physiological system through neural respiratory elements ${ }^{15}$.

This study demonstrated that Bhramari Pranayama can prove to be an effective modality to reduce stress and improve the quality of sleep when practiced even for a shorter duration of time. If future studies conducted on a larger population, using more advanced scientific tools for assessment, are able to reproduce similar results, the implications of these findings can be huge. Bhramari Pranayama, then can be prescribed as a scientifically approved modality to address health issues related to stress and diminished quality of sleep, and alongside it will also provide a myriad of other added health benefits.

\section{Conclusion}

Bhramari Pranayama when practised regularly even for a short-term period of few weeks can significantly improve sleep quality and reduce perceived stress.

\section{Clinical Implications:}

During a time when academic stress and its related adverse effects on health are on the rise alarmingly, measures like the practice of Bhramari Pranayama can prove to be an inexpensive, safe, fast and effective way to reduce stress levels and improve overall quality of sleep, along with providing a multitude of other health benefits.

\section{Limitations:}

Findings in the present study were obtained with a relatively small sample size. Future studies should be carried out on a larger and more diverse population to generalize the findings obtained here. Also, here the Sleep quality and Stress levels were assessed using 'selfrating' by the subjects. In order to further validate the above findings, a more precise measurement for these parameters should be done in future studies using better tools like Polysomnography and serum markers of stress.

\section{Conflict of Interest: None}

\section{Source of Funding: Self}

\section{References}

1. Verma S, Sharma D, Larson RW. School stress in India: Effects on time and daily emotions. Int $\mathbf{J}$ Behav Dev. 2002;26(6):500-508.

2. Deb S, Strodl E, Sun J. Academic stress, parental pressure, anxiety and mental health among Indian high school students. Int J Psychol Behav Sci. 2015;5:26-34.

3. Rentala S, Nayak RB, Patil SD, Hegde GS, Aladakatti R. Academic stress among Indian adolescent girls. J Educ Health Promot. 2019;8:158.

4. Rebello CR, Kallingappa PB, Hegde PG. Assessment of perceived stress and association with sleep quality and attributed stressors among 1st-year medical students: A cross-sectional study from Karwar, Karnataka, India. Tzu Chi Med J. 2018;30(4):221-226.

5. Jain R, Tonpay PS. Effect of pranayama on cognitive functions of medical students. Indian $\mathrm{J}$ Basic Appl Med Res. 2016;6(1):471-476.

6. Kuppusamy M, Kamaldeen D, Pitani R, Amaldas J, Shanmugam P. Effects of Bhramari pranayama on health - A systematic review. J Tradit Complement Med. 2018;8(1):11-16.

7. Manjunatha U, Bhat JS, Radish KB, Bajaj G, Shruthi P, Nayak PS et al. Effect of Bhramari Pranayama on the Acoustic and Aerodynamic Parameters of Voice in Normophonic Females. Evid Based Complement Alternat Med. 2018;2018:4176803.

8. Saraswati SS. Asana Pranayama Mudra Bandha. Reprint Edition. Munger, Bihar: Yoga Publications Trust; 2009. p.401.

9. Buysse DJ, Reynolds CF, Monk TH, Berman SR, Kupfer DJ. The Pittsburgh sleep quality index: 
A new instrument for psychiatric practice and research. Psychiatry Res.1989; 28(2):193-213.

10. Cohen S, Kamarck T, Mermelstein R. A global measure of perceived stress. J Health Soc Behav. 1983;24:386-396.

11. Kuppusamy M, Kamaldeen D, Pitani R, Amaldas J. Immediate Effects of Bhramari Pranayama on Resting Cardiovascular Parameters in Healthy Adolescents. J Clin Diagn Res. 2016;10(5):CC17CC19.

12. Vialatte FB, Bakardjian H, Prasad R, Cichocki A. EEG paroxysmal gamma waves during Bhramari pranayama: A yoga breathing technique. Conscious Cogn. 2009;18:977-988.

13. Pandey S, Mahato NK, Navale R. Role of selfinduced sound therapy: Bhramari Pranayama in Tinnitus. Audiol Med. 2010;8(3):137-141.

14. Taneja M K. Nitric oxide, Bhramari Pranayama and deafness. Indian J Otol. 2016;22(1):1-3.

15. Sathe S, Thodge K, Rajandekar T, Agrawal A. To Find Out Immediate Effect of Bhramari Pranayama on Blood Pressure, Heart Rate and Oxygen Saturation in Hypertensive Patients. Int J Cur Res Rev. 2020;12(19):193-197. 